\title{
Structural analysis of the tourism impacts in the form of future study in developing countries (case study: Iran)
}

\author{
Mohammad Nematpour and Amin Faraji
}

\begin{abstract}
Purpose - The purpose of this paper is to identify and prioritize the positive and negative impacts of tourism on the process of tourism growth at a national scale in Iran, by taking into account the reviews of previous studies, views of experts and structural analysis.

Design/methodology/approach - In this investigation, structural analysis technique has been used to identify the correlation between variables by using mix method data analysis. By using cross-impact analysis $(N \times N$ integer matrix) in the form of the Micmac method, the economic, sociocultural and environmental factors have been evaluated.

Findings - The results of the distribution of factors in the coordinate axes and the graphs between them indicate their features, and for reaching a sustainable system of tourism development, at first, priority should be given to the negative influential factors, especially the environmental fields, and then the focus should be on the decrease of the dual and risk variables as they cannot be anticipated.

Originality/value - For the rapid growth of tourism in many countries, governments ensure that policies have been heeded in designing and preparing general plans of the country to understand how the development trend is moving on. In this respect, arisen impacts of tourism system are one of the important issues during the development path and in the field of tourism future. Because of the complexity and broadness of tourism activities, these impacts have also many interconnected dimensions that should also be considered while studying tourism impacts.
\end{abstract}

Keywords Sustainable tourism, MICMAC, Structural analysis, Tourism impacts, Future study

Paper type Research paper

\section{Introduction}

What will the future of tourism look like? How do we prepare for future situations? To have a competitive role in the current globalized tourism system, it is crucial for any company, institution or country to find good answers to these kinds of questions, as evidenced by the large number of foresight agencies, organizations and departments operating around the world. Nowadays, the need for future studies to make long-term planning and strategies for proper management has become necessary. This necessity has emerged, from the social, cultural, economic, environmental and technological opportunities and threats in most developing countries such as China, Brazil or India (Villacorta et al., 2014). The study of the future of tourism system is necessary for its planning and development. In addition, it is widely understood as a means to help managers to predict the future. Using future methods to help managers and policy makers to stimulate creative thinking to consider a wide variety of coherent descriptions of alternative hypothetical futures in a systematized way in the tourism system. These predictable actions will reflect different perspectives for present and future developments, which can serve as a basis for successive actions in the system (Amer et al., 2013).

The current global growth of tourism results in formulating strategic plans, long-term planning or development trends by governments to increase their contributions such that the tourism growth
Mohammad Nematpour and Amin Faraji are both based at the University of Tehran, Tehran, The Islamic Republic of Iran.

Received 12 May 2018 Revised 17 July 2018

12 December 2018 Accepted 5 March 2019

(C) Mohammad Nematpour and Amin Faraji. Published in Journal of Tourism Futures. Published by Emerald Publishing Limited. This article is published under the Creative Commons Attribution (CC BY 4.0) licence. Anyone may reproduce, distribute, translate and create derivative works of this article (for both commercial and non-commercial purposes), subject to full attribution to the original publication and authors. The full terms of this licence may be seen at http://creativecommons.org/ licences/by/4.0/legalcode 
is benefitted. In this respect, arisen impacts of tourism system are the important issues during the development of the system. The complexity and broadness of tourism system is necessary to study tourism impacts in a specific way (Mason, 2003, p. 42). Generally, impacts related to tourism could be examined in three fields: economic, sociocultural and environmental impacts, thereby affecting the economic, social, cultural and environmental circumstances of the communities (Aref et al., 2010). The concept of sustainable development in tourism tries to make a balance between sociocultural, economic and environmental impacts as much as possible. Hence, understanding the potential of tourism impacts in development process is the basic and logical assumption of sustainable tourism planning. However, lack of sustainability in tourism can cause excessive costs and emergence of various challenges. In most cases, forecasting of the future by using non-professional ways and without trend analysis can cause many problems in carrying out the plans; therefore, a systematic look at the subjects and using expert analysis of future trends can become an appropriate basis for decreasing the negative impacts and improving positive impacts in tourism realm.

Iran has a large number and wide variety of tourism attractions, giving it a strong potential for tourism development. To reach the goal of a successful sustainable tourism development, Iran needs careful planning, systematic implementation of the plans and a continuous and effective management. Today, tourism industry in Iran needs a scientific revolution and specific changes in its structures. In this respect, planning and policymaking in accordance with the national sustainable development of tourism, economic, sociocultural, and environmental situation and trends of the country is necessary.

The objective of tourism development in Iran must be set in a relevant context and should contribute positively to the achievement of the broad economic, social, cultural and environmental objectives of the nation and country. In this regard, Iran's tourism cannot be planned or managed in isolation. Iran's tourism, especially dealing with negative impacts of tourism on environment, culture and economy, needs to be viewed professionally by using logical thinking and some more reliable scientific methods in the field of scientific research and investigation for its development.

Generally, various future study methods, based on the nature of the procedures, can be classified into qualitative and quantitative (Amer et al., 2013). In this study, we focus on cross-impact analysis (CIA) as one of the most applied quantitative methods at a national scale (Gordon, 2009). A well-known variant of CIA method proposed by Duperrin and Godet (1973) and Godet (2000) is MICMAC, which has been successfully applied in many fields.

This study aimed to analyze Iran tourism system by considering the positive and negative impacts of economic, sociocultural and environmental aspects to find out the extent of sustainability or unsustainability of the system. Implementation of long-term planning based on these findings seems possible and feasible.

This study has tried to answer the following questions:

$R Q 1$. What are the most important variables for systematic analysis of tourism impacts?

$R Q 2$. What is the role of each variable under study in economic, sociocultural and environmental tourism?

The paper is structured in three steps: the first step describes the theoretical framework and foundations and literature relating to the perception of tourism impacts in host communities. The next step describes the methodology of the research. In the last step, both the research process and the results are discussed, and implications and recommendations are highlighted.

\section{Theoretical framework}

\subsection{Study area}

Covering a wide area in the Middle East, $1,648,195 \mathrm{~km}^{2}$, and a population of approximately $80 \mathrm{~m}(2015)$ (Figure 1), it is located between $25^{\circ} 3^{\prime}$ and $39^{\circ} 47^{\prime} \mathrm{N}$ and $44^{\circ} 5^{\prime}$ and $63^{\circ} 18^{\prime} \mathrm{E}$, bordering Azerbaijan, Armenia and Turkmenistan in the north, the Persian Gulf and Oman Sea in the south, Iraq and Turkey in the west, as well as Afghanistan and Pakistan in the east (Foroutan et al., 2017). 


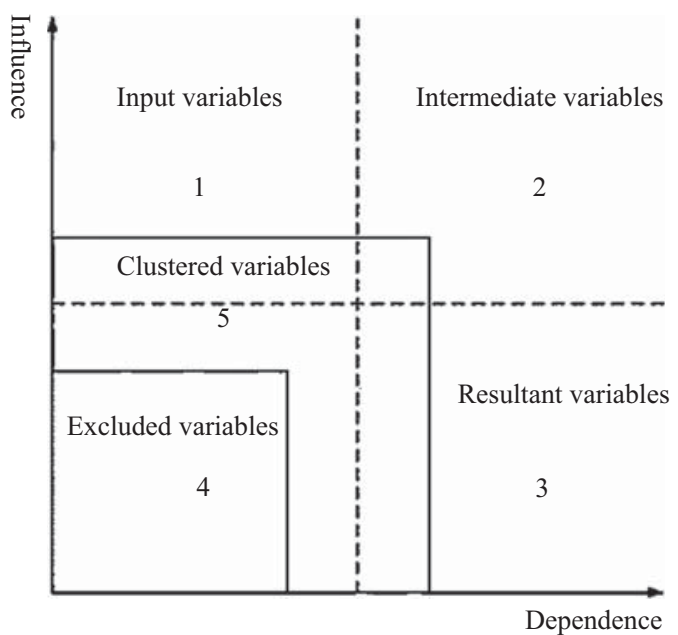

Source: Godet et al. (2008, p. 61)

Iran is a country with great history, ancient culture and a varied geography, which give rise to a wealth of substantial tourism potentials encompassing many national and man-made tourist attractions that present many activities for tourists (Ghaderi and Henderson, 2012). Iran's spirited culture makes it much wealthier than a rich developing economy. However, Iran's tourism industry has suffered from a wide range of issues over the past three decades, including the overdependency on oil revenues, political instability, the label of a terrorism-struck destination and poor management, making it unfavorable (Khodadadi, 2016). According to the current conditions in Iran, the existing gap between potential and reality tourist attractions leads to some consequences. The most important of these are the lack of infrastructure needed to support and facilitate tourism activities and the absence of a systematic tourism long-term planning and policymaking (Alavi and Yasin, 2000). Iran's Cultural Heritage, Handicraft, and Tourism Organization (ICHTO) was established in 2004. This organization has the responsibility of tourism industry in Iran (Ghaderi and Henderson, 2012). Tourism, as a part of a systematic growth strategy, has the real and affordable potential to contribute significantly to the environmental, social, cultural and economic aspirations of Iran (Alavi and Yasin, 2000). Attempts to predict and have some perceptions of probabilities of future seem to be essential for all countries, but they are most crucial for Iran's economy, society and culture. Communities seek to determine their futures whether through prophecy or systematic forms of scientific forecasting.

\subsection{Tourism system}

Since the present study tries to analyze systematically the impacts of tourism on economic, sociocultural and environmental fields, it is based on system theory (Beni, 2001; Leiper, 1990 cited in Mason, 2003). This theory is a fundamental one with a philosophical framework in long-term planning. From the system theory perspective, every phenomenon (animate or inanimate in world) is an organized collection of specific elements and relations, which is called a system. This system has a specific and meaningful function (Mahdizade, 2007, p. 40). In other words, the system is a complex whole, and its function depends on its components and interaction between them (Jackson, 2003). If we consider tourism as a system, then each one of its elements in reaching the goal is in a reciprocal relation and interaction, having influence/dependency on each other. For example, tourism seems to be an inter-systemic process such that its components have relation with each other. One of the main components is arisen impacts; its impacts are modeled as positive and negative in different sociocultural, economic and environmental dimensions. 
As mentioned above, each system consists of subsidiary systems or subsystems; in other words, each system functions as a part of a larger system. The main subsystems are known as structure and larger systems as system environment. These systems are in mutual interaction (Mahdizade, 2007, p. 40). System theory focuses on order and relation between sections and the way they function. Subjects like course of sections' organization and how they are related to each other define the properties of the system. In other words, in addition to set of sections and relations that define the components of the system, the environmental and external factors of the system are also effective in making the whole system (Chikere and Nwoka, 2015). On the contrary, there is no system in void and obviously each system belongs to external environment and a larger system such as industry, economy and society (Weihrich et al., 2008).

Beni (2001) presented his tourism system as an open system that can influence and be influenced by the other systems with which it interacts. This system is composed of three sets:

1. Environmental relationships are composed of external settings in tourism system, which include cultural, social, ecological and economic subsystems. Each one of these external settings is influencing internal elements.

2. The structural organization consists of the superstructure and infrastructure subsystems.

3. Operational actions contain the dynamics of the tourism system. They include supply, market, demand, production, distribution and consumption subsystems. This holistic approach can be considered in all components and dimensions. Tourism seems to be a dynamic and open system that has effects on supply and demand. From an overview perspective, the tourism market, as well as infrastructure and superstructure are systemically affected by their environment. In other words, the aim of system is to understand the operation of tourism and present the systems that precede it. This system explains each of the elements of tourism from its interrelation with other disciplines and the origin of controlling and dependent subsystems. Tourism System (SISTER) is introduced as a set of procedures, ideas and principles, and ordered logically with the intention of seeing the operation of the tourist activity as a whole.

\subsection{Tourism impacts}

Tourism is one of the important types of human activities that has important impacts on local community. These impacts on destination societies, where tourists are in touch with living, economic and sociocultural environments of these societies, are conspicuous and visible. Therefore, categorizing tourism impacts in three categories, sociocultural, economic and environmental, is typically an accepted practice (Mason, 2003, p. 29):

1. Economic impacts of tourism: generally, economic dimension is the most important reason for the positive attitude of local community toward tourism. However, this economic dimension can include the evaluation of positive and negative aspects depending upon the level of development of countries. Some of these impacts are as follows: increase in income (Andereck et al., 2007), generation of employment opportunities (Deery et al., 2012), improvements in community infrastructure and public facilities (Yoon et al., 2001), seasonality (Wu and Chen, 2015) and so on.

2. Sociocultural impacts of tourism: these impacts are defined as factors influencing customs, habits, social life, beliefs and values of native inhabitants of tourism destinations. Interactions that take place between local people and tourists can result in new social and cultural opportunities for both sides or, on the contrary, can generate feelings of distress, pressure, congestion, etc. (Andereck et al., 2005).

3. Environmental impacts of tourism: tourism can result in preserving and protecting the resources or can result in destruction or damaging of resources with attractive, yet fragile, settings. These impacts can be in form of pollution increase, improvement of the appearance of host community, etc. However, negative environmental impacts are ignored by local community in favor of tourism advantages (Yoon et al., 2001; Liu and Var, 1986).

In passing, it should be noted that confronted by research in the triple impacts of tourism is the dominance of a quantitative paradigm that has not facilitated a deep and clear 
understanding of the impacts and how these impacts were formed. The research tries to date and provide lists of impacts, more importantly, a deep understanding of future impact trends in the tourism system and how these could be conducted in the future of the tourism system, if necessary.

\subsection{Sustainable development of tourism}

Generally, sustainable development is a development that meets the needs of the present without compromising the ability of future generations to meet their own needs (Brundtland, 1987). Another definition of sustainable development given by Co-operation and Development (2001) is about the coordination of economic, social and environmental aspects (Dias et al., 2014; Shaker and Sirodoev, 2016). This also applies to tourism, wherein the basic concepts of general sustainable development have been gradually translated into the concept of sustainable tourism development (Postma and Schmuecker, 2017). From the point of view of WTO[1], the core principles of sustainable tourism development are as follows: to provide high-quality experience for visitors; to maintain the quality of the environment; and to improve the quality of life of the host community, on which both the host community and the visitors depend (Mill and Morrison, 2002). In this respect, local governments should be more careful and responsible to the local people and visitors who may be affected by tourism in all its positive and negative manifestations (Burns and Holden, 1997).

\subsection{Importance of future studies}

In general, futures studies refer to the scientific study of future developments in the terms of possibility, desirability and probability. There are two different attitudes of the future in developed and developing countries: knowledge-based society and sustainable society. In developing countries, the concept of sustainable development is commonly found according to the need to maintain the fundamentals of existence and production, worldwide and on a long-term basis, and to distribute the profits of natural and scientific technological resources more fairly (Kreibich et al., 2012). In terms of planning the future, forecasting functions are just one approach among many that are essential to develop a good plan. Most of the planners use the future study to help in planning for the future and for policymaking and strategic planning. Future studies cannot always be beneficial and effective. Sometimes, they challenge the current framework and circumstances, and they can also be more disruptive instead of seeking to make strategy more effective (Inayatullah, 2013). Future planning seeks to collect, integrate and link relevant information to provide effective and organized solutions for building strategy and reaching it. Furthermore, using tools for analysis of behavior and forces of social actors and crucial variables in order to develop strategies is the main goal of future studies (Apodaca, 2001; Georghiou et al., 2012). Generally, as claimed by Glenn, future would never been known or anticipated accurately and completely. In this regard, intention to research the future must be explored, created and investigated systematically, and desirable future can be attained by improving policy decisions (Glenn, 2003).

\subsection{Cross-impact analysis}

There are many future research methods, ranging from qualitative to quantitative or simplistic to complex (Glenn and Gordon, 2003). There are many criteria regarding the choice of the methods of future studies. The choice must be depend on the existence problem, potential resources and the level of progress of planners. There are some important and best-known methods in this field of study, including the Delphi method, scenario writing, simulation and CIA (Schnaars, 1987).

Although the future is a perspective event, caused by the interactions of many dynamic and evolving events over time, producing information only in an isolated way is the fundamental limitation of numerous futurology-based research methods. It means that events and developments are surveyed without considering their possible impact on each other. To examine the behavior of a system in the future, a set of variables, crucial to systematically explain the system and their relationships that will shape the future, needs to be analyzed. These interrelationships between system's variables are called cross-impact (Asan and Asan, 2007a, b). The cross-impact is the best-known method used to analyze interrelationship between the variables. For systematic description of all potential modes of interaction between a given set of 
variables and for the assessment of the strength of these interactions, the CIA method is used (Schlange and Jüttner, 1997).

Theodore, Gordon and Olaf Helmer were the first ones who originally developed the cross-impact method (Gordon and Hayward, 1968). Since 1966, several researchers have developed many versions of CIA method (Duperrin and Godet, 1973; Godet, 2000; Gordon, 2009). According to the previous studies, three groups of these versions can be categorized: quantitative, qualitative and mixed method CIA. There is a big difference between quantitative and qualitative versions, that is, mathematical model relating to the variables (quantitative) and experts' estimates of the relationships - probabilities or impact - among the variables (qualitative) (Duperrin and Godet, 1973). The aim of the $\mathrm{CIA}$ is to reduce the complexity of the system and to identify the important and key variables that should be studied. There are some important steps in this classification. The exploration of the key and crucial variables means that any change in key variables will affect the whole system and they will have more importance in the future of the system (Schlange and Jüttner, 1997).

2.6.1 Structural analysis. We can explain the structural analysis as a system that has a set of interrelated variables. In this system, there is a network of the interrelationships between variables, and their analysis is essential to understand the evolution of the system in the future (Chine et al., 2017). From the point of view of the structural analysis functions, we can point out to identify the structure of the relationships between the quantitative and qualitative variables, which characterize the system under study (Chine et al., 2017). Furthermore, we can describe a system by using a interconnect matrix in structural analysis. The important output of structural analysis is the identification of key variables controlling the evolution of the system under study (Chine et al., 2017).

The structural analysis is based on the CIA method. In fact, the structural analysis method is a variant of the original CIA method, taking into account not only the direct relations but also the indirect ones (Cabrera et al., 2002).

2.6.2 Structural analysis with MICMAC method. The MICMAC (cross-impact matrix multiplication applied to classification) is a method for structural analysis and a well-known variant of CIA method proposed by Duperrin and Godet (1973) and Godet (2000). This method is aimed at determining the most important variables within a system among a set of variables, initially specified by an expert committee, and it analyzes the importance of a given set of variables through a matrix. In other words, the experts define the key variables of the system to establish their role in the system (Villacorta et al., 2014). The MICMAC method consists of the following three phases (Arcade et al., 1993):

1. gathering the inventory of variables;

2. describing of the relationships between variables; and

3. the identification of key variables.

To describe the relationship between variables in phase (2), an $(n) \times(n)$ integer matrix in a quantitative form must be sounded by an expert panel. This matrix is known as MDI or matrix of direct influence. Each cell of $\mathrm{MDl}_{i j}$ shows the impact of each "i" variable on "j" variable. The numbers from 0 to 3 give value to these impacts and are described as follows: number 0 shows no relation between variables, number 1 shows weak relation between variables, number 2 shows moderate relation between variables and number 3 shows strong relation between variables.

Identifying the key variables is a very important step that shows the level of variable's importance through the integer matrix. Outputs show the type of impacts and their relationship to others, and this has a vital role in presenting the best management planning.

There are two procedures to accomplish this: direct and indirect. In accordance to the nature of the data, analysis has been done by using the direct method. The direct method ranks the variables according to their direct influence/dependence on/of the others. In this regard, the elements of MDI matrix in the form of the kth row and $k$ th column have been added by MICMAC to obtain the global direct influence. As said above, we can have following formulas:

$$
I_{k}=\sum_{(j=1)}^{n} \operatorname{MDI}(K, j)
$$


and dependence, in the form of:

$$
I_{k}=\sum_{(i=1)}^{n} \operatorname{MDI}(i, k)
$$

of the $k$ th variable, respectively.

With this information, an influence ranking $N_{1}$ and a dependence ranking $N_{D}$ are built by sorting the variables decreasingly according to their influence and dependence. Both rankings serve as a first indicator of the importance of each variable in the system (Villacorta et al., 2014; Asan and Asan, 2007a, b).

According to analysis and outputs resulted from MICMAC, the chart is a two-dimensional map where the vertical axis represents the degree of influence variables and horizontal axis represents the degree of dependence. The axes divide at four quadrants and five zones; in other words, the variables are located at five zones and are divided in the following five categories (Villacorta et al., 2014; Asan and Asan, 2007a, b; Godet et al., 2008; Saricam et al., 2012):

1. Input/Influential variables: these variables are inputs, they are located at northwest part of the chart and the most of the system is dependent on them. In fact, the level of influence of these variables on other ones is much higher than the level of their dependency in future. In other words, system is strongly dependent on these variables and they are defined as determinative and key variables of system behavior, and therefore they are called as the main drivers of system.

2. Intermediate variables: these variables are in the northeast part of chart and can be very influential and very dependent at the same time. Due to their unstable nature, they may have influence on other variables and sometimes even depend on influential variables.

3. Output/Dependent variables: these are resultants, they are located in southeastern part of the chart and have a low level of influence and high level of dependency. In other words, they are sensitive to influential and intermediate variables' changes. In addition, they are considered as output variables in the system.

4. Excluded variables: low level of influence and dependency is considered a characteristic of these variables in the southwestern part of the chart. They are identified as independent variables in the system. These variables seem to be completely out of chart. Basically, they neither can interfere in the system's function nor use the system. In other words, they have little influence on the system.

5. Clustered variables: they have been introduced as variables, such that the system cannot make certain decisions about them. In other words, because of their placement in border areas of each four sections, the possibility of these variables joining one of the four sections is high.

\section{Methodology}

The study period spanned from November 2015 to September 2016. In this work, we focus on perspective structural analysis in the form of CIA (Gordon, 2009). As pointed out previously, the perspective structural analysis is a method that normally developed in three phases: inventory of the variables, describing the relationships between variables and identifying key variable by analyzing the variables and their relationships (Arcade et al., 1993).

\subsection{Phase 1: listing the variables}

Perspective structural analysis is based on expert's opinions; thus, identifying people with a good knowledge of each structural analysis was critical. In this regard, a purposive sampling method was used to choose the experts; a purposive sampling is a non-probability sample that is selected on the basis of the characteristics of a population and the objective of the study. This kind of sampling is also as judgmental, selective or subjective sampling. Purposive sampling strategies differ from probability (or random) sampling strategies. Researches must be able to explain the use of purposive sampling in any particular study and discuss the implications for the research results (Devers and Frankel, 2000). 
The reason for applying a purposive sampling in this paper is selection of a group of experts who have a deep understanding or are information rich in a specific field (Neuman, 2007), and they can provide full insight into the research questions (Devers and Frankel, 2000). Akins et al. (2005) pointed out that panels have been conducted with just about any size. Typical panels seem to fall in the category of 10-100 members and consist of either two or three expert groups, again depending on stakeholder interest (Avella, 2016). Thus, the sampling size of the study consisted of 27 experts as academicians. They were decision-makers, professionals and consultants at the same time, in the fields of tourism, economy, geography and urban and regional planning. These experts were chosen among academic staffs of Tehran University and Science and Culture University (Table Al).

The next step in this phase is compiling a list of the most relevant variables in the system. Generally, list of variables does not exceed 70 or 80 variables (Chine et al., 2017). Then, the final variable list is decided by consensus, and each variable of the research must be clearly defined, characterized and understood by all participants. To achieve the goal of the study, we only need to measure the direct relationships between the indicators; this is achieved through the MICMAC method (Arcade et al., 1993).

\subsection{Phase 2: describing the relationships between variables}

The data collection tool was a self-developed questionnaire designed in the form of CIA matrix whose variables were determined by the first phase. The variables identified in the first phase were entered in the analysis matrix, and the experts determined the degree of influence/ dependency between them. Indexes used in this study cover economic, sociocultural and environmental impacts of tourism. The collected data were categorized on the basis of known factors to understand the level of variables' impacts on each other and to understand the necessity of systematic analysis in Iran's long-term planning for tourism. In this phase, strategic variables that contributed to Iran's tourism development were categorized and analyzed. For this purpose, CIA method using MICMAC method was performed to assess the influences between variables (from 0, no influence, to 3 , strong influence) (Dewangan et al., 2015). Figure 2 shows a hypothetical example of analysis matrix for five hypothetical variables, $V 1-V 5$; this is an example of an influence interrelation network: $V_{i} \rightarrow V_{j}$ indicates that $V_{i}$ influences $V_{j}$.

The sign (positive/negative) of each influence is recorded (to be used in the final analysis) but not introduced in the matrix, because this would make the next analysis impossible.

\subsection{Phase 3: identifying the roles played by the variables}

In this phase of structural analysis, we use the MICMAC software to calculate direct influence and dependence of each variable (the sums of each row and column, respectively). The MDI is then

Figure 2 Matrix of direct influences (MDI)

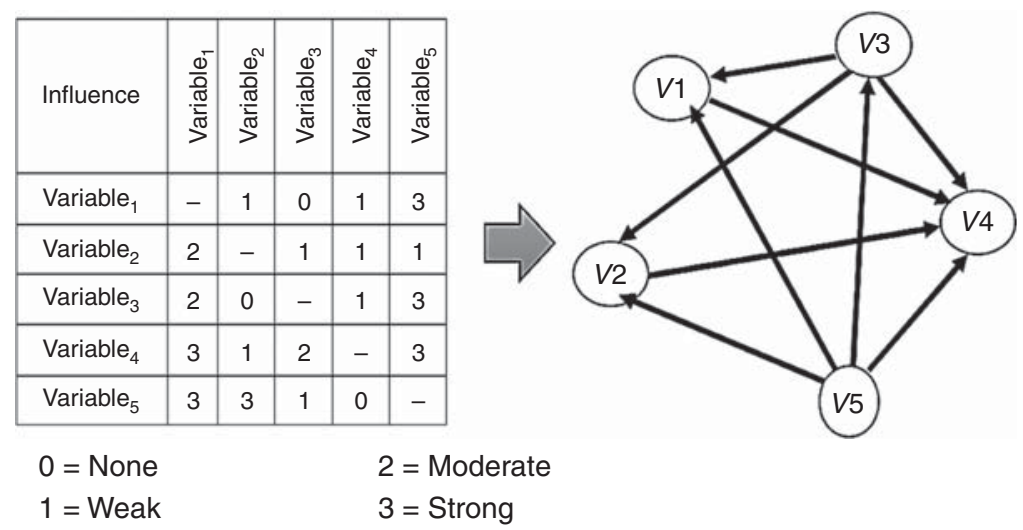


increased to the second, third, ..., nth power, until the overall rating of the influence and dependency of the variable remain constant. The outputs of MICMAC show that direct and indirect influence/ dependency maps can be plotted, revealing variable clustering. Their positions indicate the different functions played by variables in the system (input/influential variables, intermediate variables, output/ dependent variables, excluded variables and clustered variables). These maps show the present and future participants' understanding of the system and what they perceive as potentialities (variables with high influence and dependence capacity), opportunities (variables with medium influence and dependence capacity) and constraints (variables that cannot be influenced) for change. Structural analysis also identified networks or loops of interrelated variables through the construction of influence graphs (Delgado-Serrano et al., 2016).

\section{Finding and discussion}

According to Table I, the list of understudied variables for structural analysis (positive and negative tourism impacts on economic, sociocultural and environmental fields) is presented. In other words, in this study, experts initially defined 56 variables to be considered in the analysis, which can be found in Table I; these 56 variables were detected as primary variables and were analyzed by Micmac software. The matrix dimensions for positive economic impacts were $(11 \times 11)$, for negative economic impacts were $(8 \times 8)$, for positive sociocultural impacts were $(10 \times 10)$, for negative sociocultural impacts were $(12 \times 12)$, for positive environmental impacts were $(6 \times 6)$ and for negative environmental impacts were $(9 \times 9)$.

According to the nature of plotted maps (Figure 3) and identified networks or loops of interrelated (influence graphs) (Figure 4), the tourism system and its related variables are given as follows.

Input variables in northwestern part including source of foreign exchange (N3), earning job diversity and the creation of new business opportunity (V5), helping to boost GDP (V6) and thriving local market (V8) are considered as determinative and influential variables that influenced many other economic variables in the system. On the other side of this table and in its northeastern part of the map, intermediate or strengthening variables including increase in income (V1), direct and indirect employment opportunities creation (V2), investment improvement (V4) and infrastructure improvement (V10) are found. These variables in some cases can have influence even on influential variables. Among this group of variables, improvement of investments and income increase because of their own unstable characteristic and potential to change into variables playing the main role in the system are considered as a potential breakpoint for the system. Due to these characteristics, risk variables are their secondary name. In addition, the creation of job opportunities and infrastructure improvement variables are considered as target variables and from a systematic plan as intended variables. Both of them can be considered crucial factors in the way of sustainable tourism development of the Iran. These variables instead of predetermined goals indicate general goals for the whole system. In southeastern part of the map, assistance in poverty reduction and wealth distribution in better ways (V9) and improvement in the quality of life (V9) can be seen as output variables of the system. These variables have a high level of dependency and low level of influence. In other words, they have a special sensitivity toward the changes occurring in influential and intermediate variables. In southwestern part, there are variables that have least dependence and influence that seem to be out of system and have the least interference in the future of system. Competitiveness (V7) in Iran tourism industry has this characteristic.

According to systematic relations between variables related to positive economic impacts of tourism system, these variables can be shown in an identified network or loop of interrelated (influence graphs) (Figure 4). Based on what is shown in this graph, most of the variables have a mutual relationship with each other. Only in cases such as source of foreign exchange (V3), poverty decrease, wealth distribution (V9), strong and strongest direct influences do not exist, and these variables have weak and weakest direct influences.

The negative economic status and impact of tourism is show in Figure 5. Input variables in northwestern part of the map including scarcity of some essential commodities in tourist seasons (V18), attracting non-local workers for the lack of local's knowledge and expertise (V19), represent influential variables. In northeastern part of the map, variables like increases in the price of real estate and land (V12), raising the costs of living (V13), inflation (V16) and overdependency on tourism without considering other expenses opportunities (V17) are considered 
Table I List of variables

\section{Dimension Variables}

Economic

V1_Increase in income

V2_Direct and indirect employment opportunities creation

V3_Source of foreign exchange earning

V4_Investment improvement

V5_Job diversity and the creation of new business opportunity

V6_Helping to boost GDP

V7_Competitiveness

V8_Thriving local market

V9_help in poverty reduction and wealth distribution in better ways

V10_Infrastructure improvement

V11_Improvement in the quality of life

V12_increases in the price of real estate and land

V13_Rise in the cost of living

V14_Seasonality of tourism and the lack of job security

V15_Tourism revenue leakage

V16_Inflation

V17_Overdependency on tourism without considering other expenses opportunities

V18_Scarcity of some essential commodities in tourist seasons

V19_Attracting non-local workers for the lack of local's knowledge and expertise

Sociocultural V20_Improvement in the quality of educational, recreational, social and health facility

V21_Cultural development and public awareness

V22_Branding the region

V23_Reduction in migration pressures

V24_Identity construction and community attachment

V25_Exchange and promotion of local culture

V26_Enhancement in the level of safety and security

V27_Increase in participation and social capital

V28_The revival of local values

V29_Creation of desirable image of host community

V30_Increasing social gap phenomenon

V31_High population, density, overcrowding and increase the volume of traffic

V32_Reducing mental capacity of Iran's tourist destinations

V33_Increase in social disorders

V34_Changing the demographic composition

V35_Increase in health problems

V36_Distortion of local values

V37_Increase in problems of local residents to use public services and facilities

V38_Consumerism

V39_Demonstration effects

V40_Commodification of the culture

V41_Weakening the social philanthropy relationships

Environmental V42_Increase in environmental awareness

V43_Promotion of green architecture

V44_Improvement of the quality of the environment

V45_Increasing the level of green zones such as parks etc.

V46_Management of waste products

V47_Prohibited area and protected areas to attract more tourists

V48_Increasing air and water pollution

V49_Noise and visual disturbance (visual pollution) and olfactory pollution
Source

Dogru and Bulut (2018), Marzuki (2011)

Deery et al. (2012), Gursoy et al. (2007)

Edwards et al. (2008), Esmaeil Zaei and Esmaeil Zaei (2013)

Johnson et al. (1994), Liu and Var (1986)

Deery et al. (2012)

Edwards et al. (2008)

Lee et al. (2003), McGehee and Andereck (2004)

Edwards et al. (2008)

Aref (2011), Goeldner and Ritchie (2012, p. 24)

Choi and Sirakaya (2006), Marzuki (2011)

Marzuki (2011)

Wanwara-Mbugua and Cornwell (2008)

Easterling (2008), Deery et al. (2012)

Wu and Chen (2015), Belisle and Hoy (1980), Sheldon and $\operatorname{Var}(1984)$

Tohidy (2011)

Lundberg (2016), Wu and Chen (2015), Liu and Var (1986) Uysal (2015)

Wanwara-Mbugua and Cornwell (2008)

Uysal (2015)

Deery et al. (2012), Zhou (1986)

Sharpley (1994)

Tosun (2002)

Deery et al. (2012)

Sharpley (2014), Lin (2001), Drumm et al. (2004)

Lundberg (2016), Sharma et al. (2008)

Hall et al. (2004), Aref (2011), Deery et al. (2012)

Jaafar et al. (2017), Williams et al. (1995)

Burns and Holden (1997)

Chiu et al. (2016), Cui and Ryan (2011), Choi and

Sirakaya (2006)

Goeldner and Ritchie (2012)

Andereck et al. (2007), Goeldner and Ritchi (2012)

Dyer et al. (2007)

Deery et al. (2012), Getz (2008)

Jackson and Inbakaran (2006)

Choi and Sirakaya (2006)

Wu and Chen (2015)

Deery et al. (2012); Getz (2008)

Dogan (1989), Wanwara-Mbugua and Cornwell (2008)

Cui and Ryan (2011)

Burns and Holden (1997)

Perez and Nadal (2005)

Chiu et al. (2016)

Holden (2009), Chiu et al. (2016)

Inskeep (1991)

Deery et al. (2012), Zhou (1986)

Holden (2009), Vishwanatha and Chandrashekara (2014)

Holden (2009), Vishwanatha and Chandrashekara (2014)

Inskeep (1991), Rizal and Asokan (2014), Zhou (1986)

Rizal and Asokan (2014), Zhou (1986) 


\section{Table I}

V50_Destruction of natural and historical resources due to uncontrolled tourism development

V51_Open spaces reduction due to uncontrolled construction

V52_Increase in waste generation

V53_Soil erosion and landslides density and compactness of the soil surface

V54_Reduction of natural resources per capital

V55_Reduction of physical capacity of the tourist destinations

V56_Ecosystem degradation and vegetation destruction (flora and

fauna destruction)
Deery et al. (2012), Easterling (2008)

Choi and Sirakaya (2005), Easterling (2008)

Choi and Sirakaya (2006), Marzuki (2011), Rizal and Asokan (2014)

Andereck (1995), Getz (2008), Rizal and Asokan (2014)

Andereck (1995), Easterling (2008)

Getz (2008)

Andereck (1995), Zhou (1986)

Figure 3 Direct economic positive influence and dependence

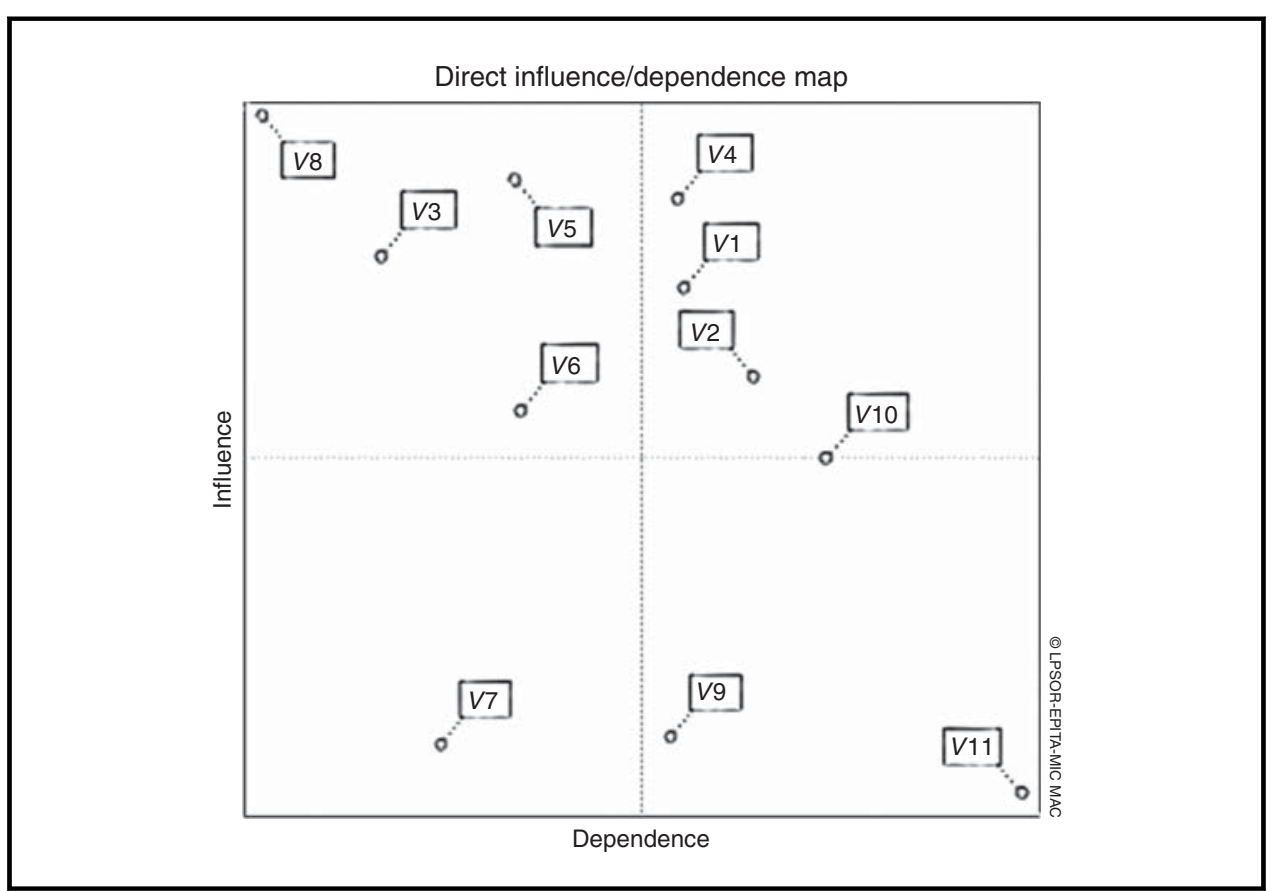

as intermediate variables. Among these, variables such as overdependency on tourism without considering other expenses opportunities, inflation and increase in land price have a high potential to become main variables and are specified as risk variables. In addition, raising the costs of living is recognized as a target variable. As Figure 5 demonstrates, there is no variable in southwestern part of the map. In other words, no variable can be found that has a special sensitivity toward changes in influential and intermediate variables. In southwestern part, variables with the least influence and the least dependence can be seen. These variables, somehow, have the least interference in the system work. Seasonality of tourism and the lack of job security (V14) and tourism revenue leakage (V15) are present in this area of the system's map. Figure 6 demonstrates the existing interrelationships between variables in form of a graph, and it represents the intensity of mutual relations between variables.

According to outputs (positive sociocultural variables) gained from MICMAC software in Figure 7, there is no influential or dependent variable in northwestern and southeastern of the map. In northeastern part, variables like cultural development and public awareness (V21), branding the region (V22), identity construction and community attachment (V24), exchange and promotion of local culture (V25), the revival of local value (V28) and creation of desirable image of host community (V29) are considered as intermediate variables. In addition, creation of a desirable 


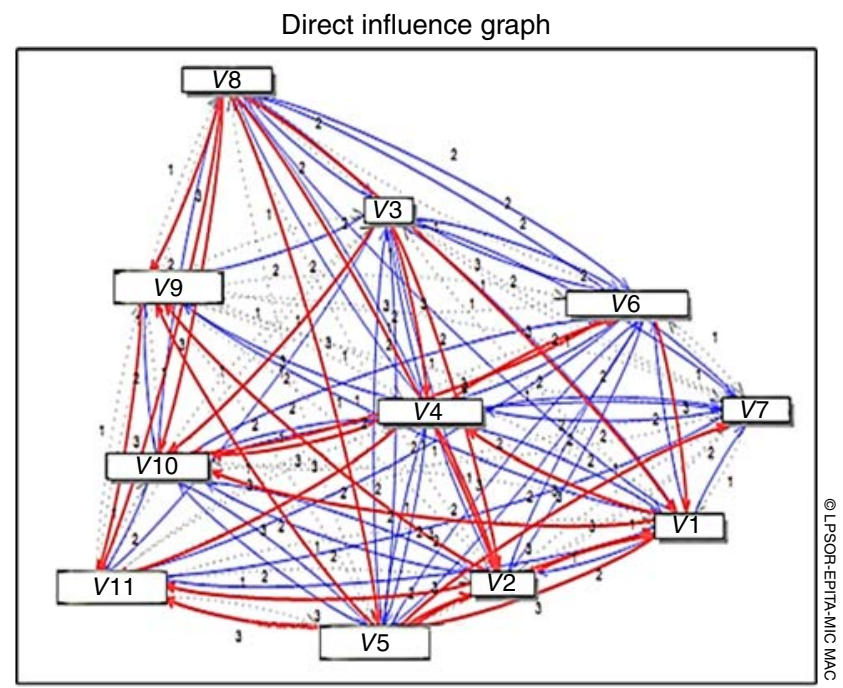

Weakest influences

- Weak influences

- Moderate influences

- Relatively strong influences

- Strongest influences

\section{Figure 5 Direct economic negative influence and dependence}

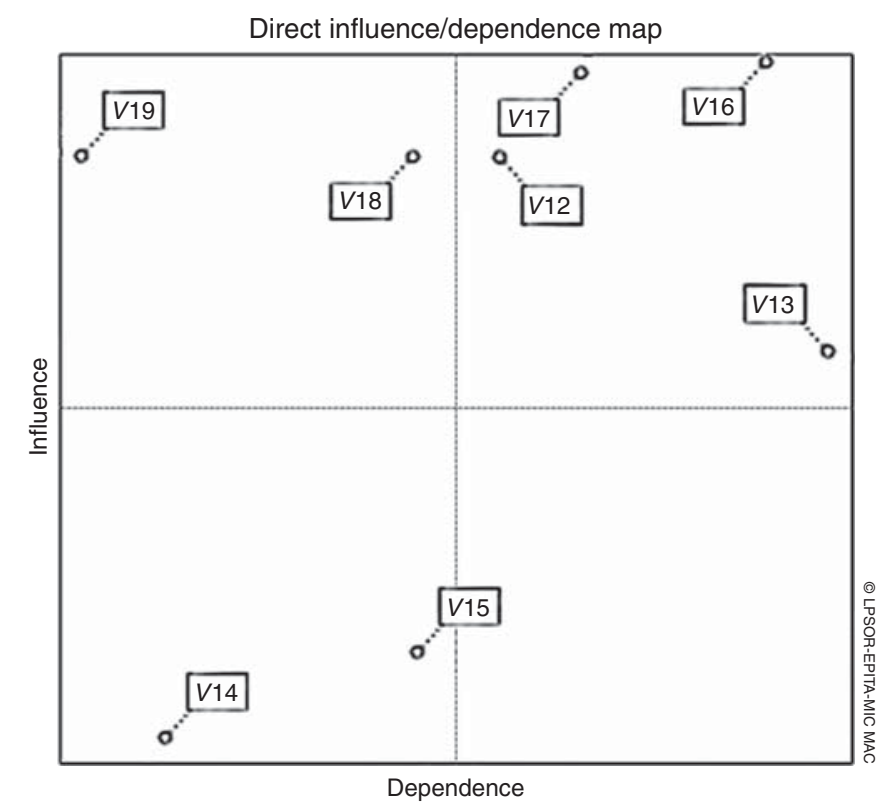

image of host community is specified as a risk variable and region branding as a target variable. In southwestern part of the map, reduction in emigration pressures (V23) is considered as a negligible variable. From the system stability perspective, the distribution in the risk line of the map shows unstable conditions and unexpectedness of system behavior. Therefore, this manner of distribution and placement can be defined as an unstable system. Also, Figure 8 represents 


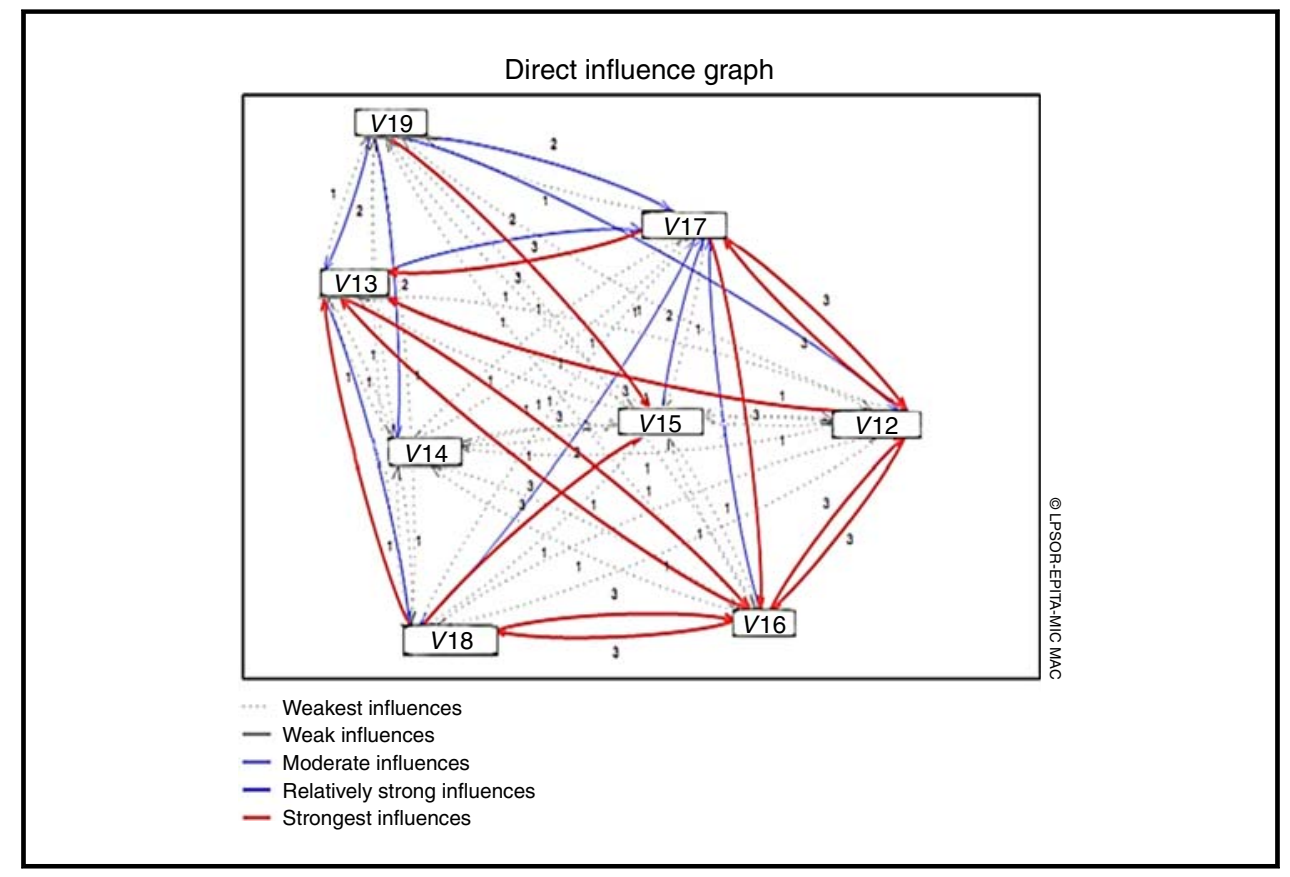

Figure 7 Direct sociocultural positive influence and dependence

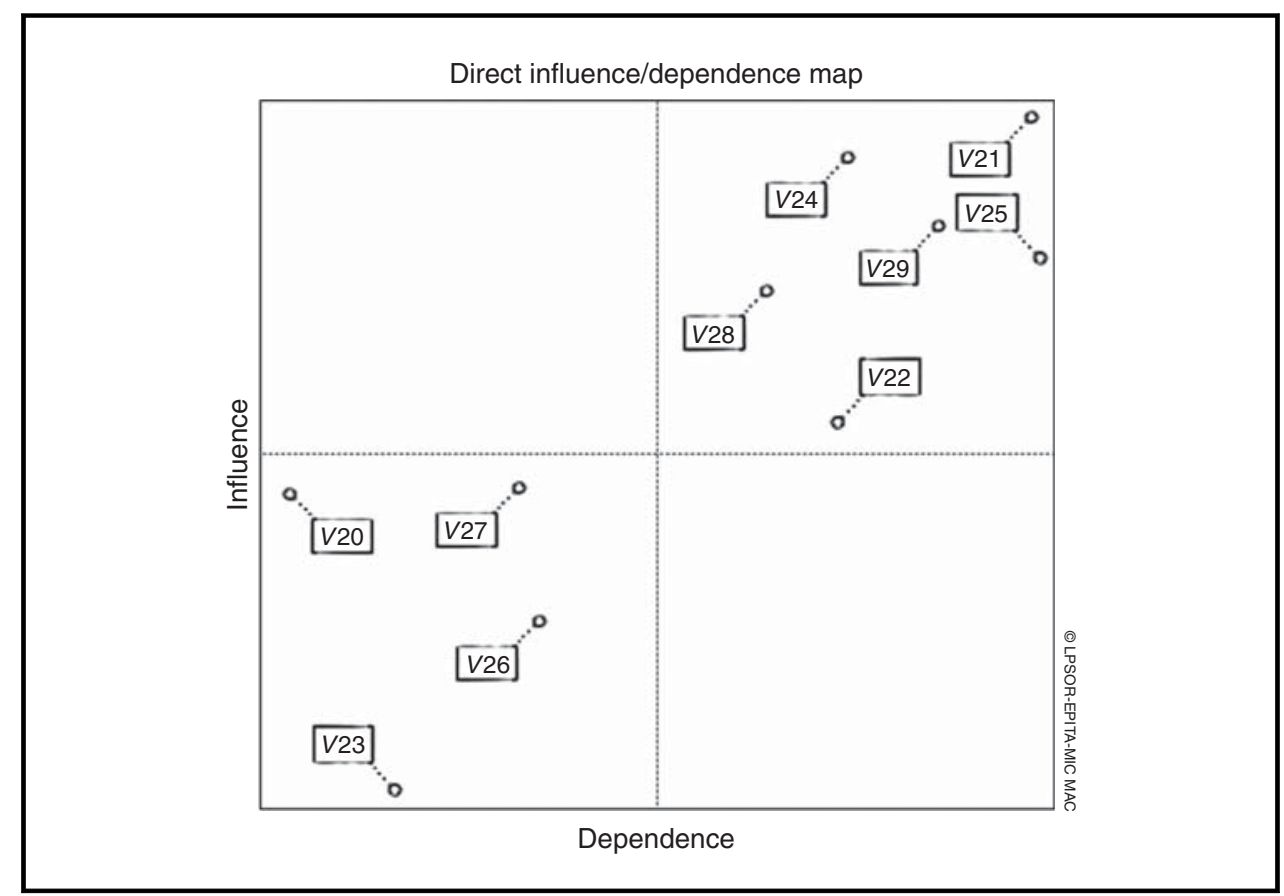

the interrelationships of many variables as having mutual and strongest strong/influence. Among those some variables such as reduction in emigration pressures, enhancement of the level of security and safety, improvement in the quality of educational, recreational, social and health facility have weakest influence on each other and another variables.

In Figure 9, high population density, overcrowding and increase in the volume of traffic (V31) and change in the demographic composition (V34) are considered as influential variables. 


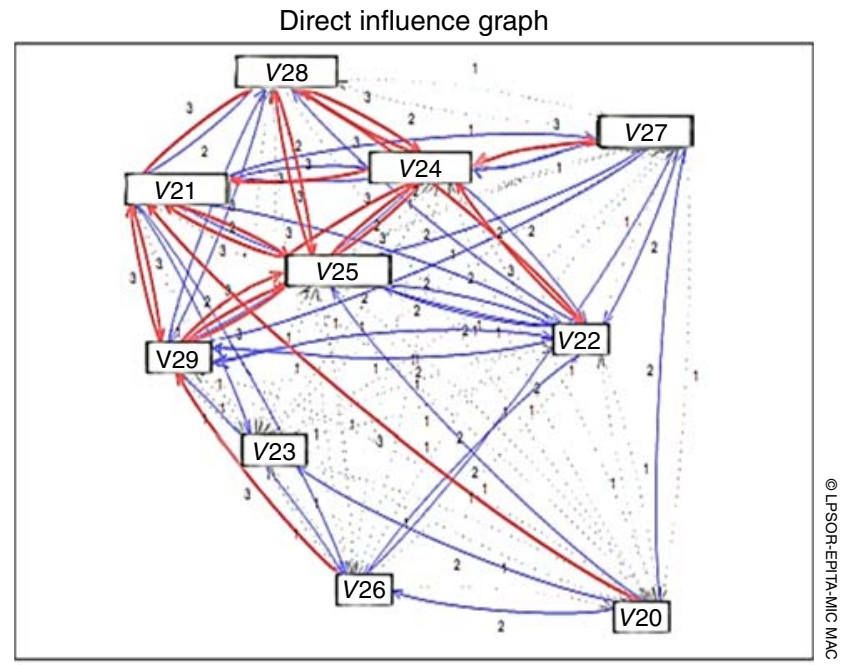

Weakest influences

- Weak influences

- Moderate influences

- Relatively strong influences

- Strongest influences

Figure 9 Direct sociocultural negative influence and dependence

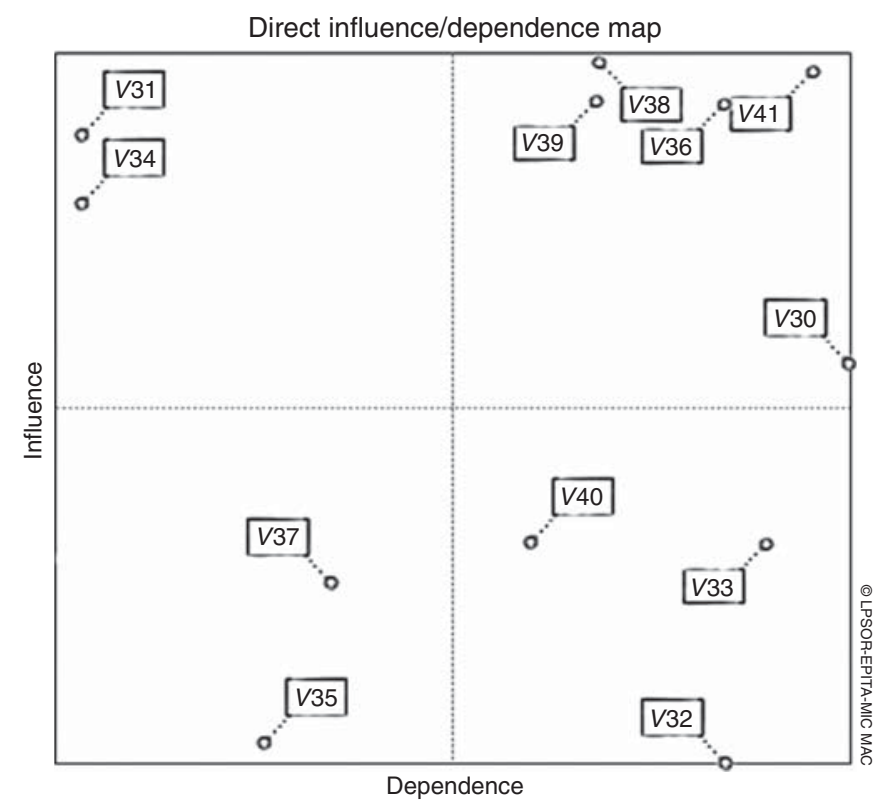

Increasing social gap phenomenon (V30), distortion of local values (V36), consumerism (V38), demonstration effects (V39) and weakening of the social philanthropy relationships (V41) are highlighted as intermediate variables. Among them, increasing social gap phenomenon is specified as a target variable. The reduction in the mental capacity of Iran's tourist destinations (V32), increase in social disorders (V33) and commodification of the culture (V40) are specified as 
dependence variables of the sociocultural negative impacts system. Furthermore, two variables increase in health problems (V35) and increase in the problem of local residents to use public services and facilities (V37) - are recognized as negligible variables. Figure 10 demonstrates the interrelationships of the variable of sociocultural negative impacts system. Variables such as high density of population, increase in local community problems, change in population composition and increase in social disorders have strong/strongest influence.

Based on outputs, positive tourism environmental variables are represented in Figure 11. Results showed that the system is partly stable. In other words, increase in environmental awareness (V42) and improvement of the quality of the environment (V44) were introduced as influential and dependent variables, respectively. In addition, promotion of green architecture (V43) is specified as a risk variable. In this system, increasing the level of green zones, such as parks, etc., (V45), is highlighted as a target variable. Furthermore, management of waste products (V46) and creation of hunting prohibited area and protected areas to attract more tourists (V47) were recognized as independent (negligible) variables. Figure 12 states that an increase in environmental awareness, improvement of the quality of the environment, promotion of green architecture and an increase in the level of green zones, such as parks, are the variables that have strong/strongest influence.

Finally, Figures 13 and 14 explain the negative environmental impacts system in Iran. As shown by spotted map, the open spaces reduction due to uncontrolled construction (V51) is specified as an influential variable. Furthermore, the decrease of national resources per capita and increase of different pollutions were identified as dependent variables. The destruction of natural and historical resources due to uncontrolled tourism development (V50) and ecosystem degradation and vegetation destruction (V56) are specified as intermediate variables (risk variable and target variable, respectively). On the contrary, the decrease in physical tolerance capacity is identified as secondary leverage and soil density and erosion (V53) and also an increase in waste generation (V52) are specified as independent variables. Figure 14 shows that the interrelationships between variables have a strong/strongest influence.

\section{Conclusions}

In this study, a novel methodology has been presented with a long-term planning in the form of structural analysis. The purpose of structural analysis is to explore the key variables of a system

Figure 10 Sociocultural negative influence relations

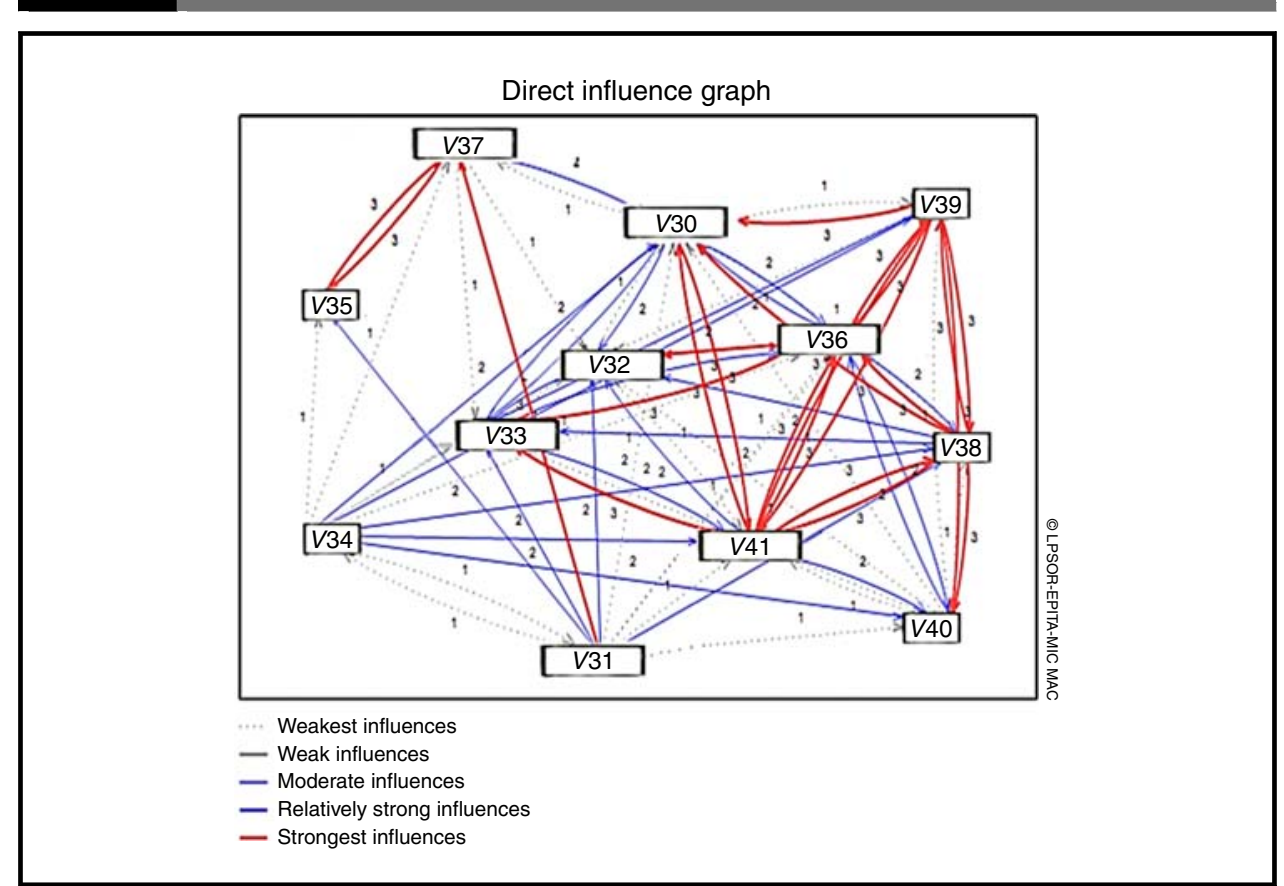

VOL. 5 NO. $32019 \mid$ JOURNAL OF TOURISM FUTURES $\mid$ PAGE 273 


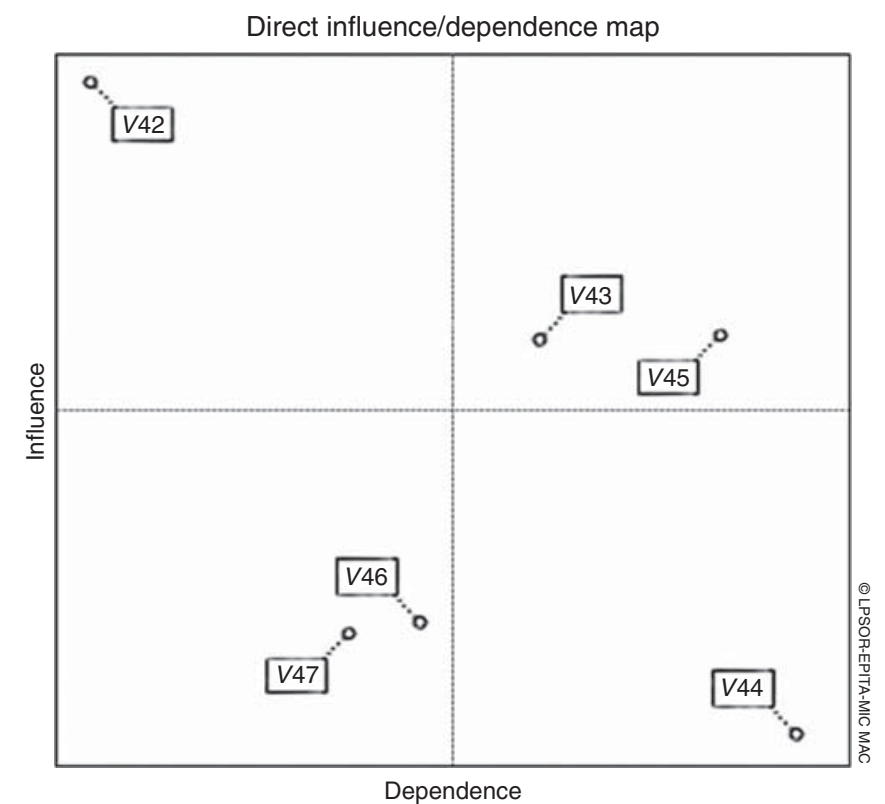

Figure 12 Environmental positive influence relations

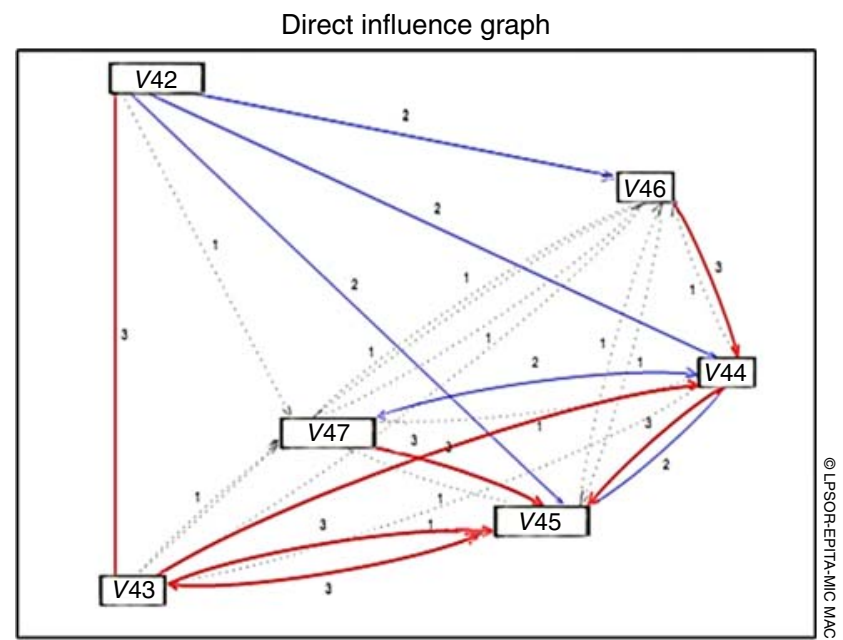

Weakest influences

- Weak influences

- Moderate influences

- Relatively strong influences

- Strongest influences

and identify their influence or dependency, thereby playing role in reducing system complexity, and subsequently, it can be helpful to consider the future of evaluating strategic decisions (Benjumea-Arias et al., 2016).

To study the future of tourism system and to set a propitious long-term planning, we should consider the concept of system; system theory is relatively a comprehensive approach to 


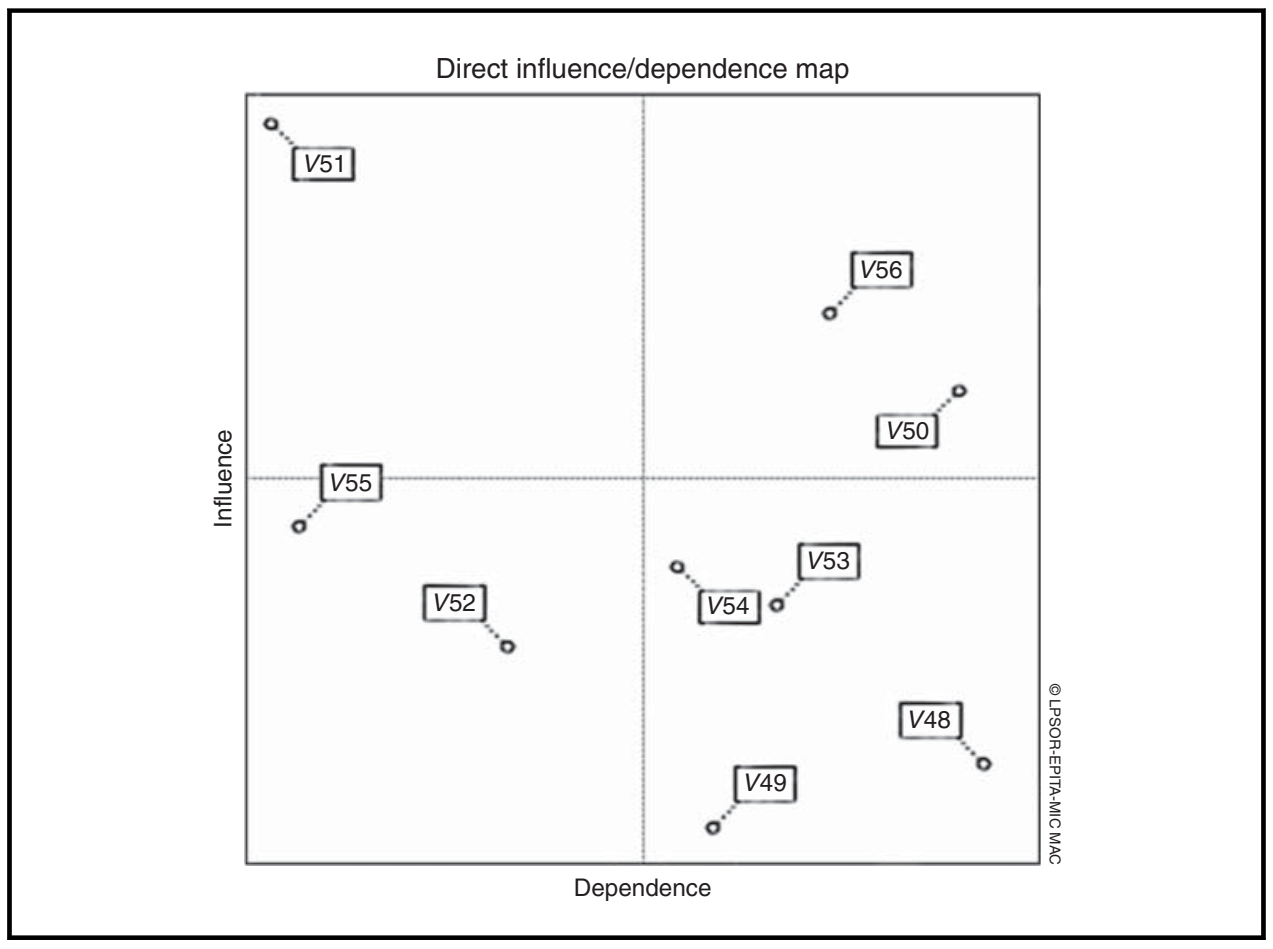

Figure 14 Environmental negative influence relations

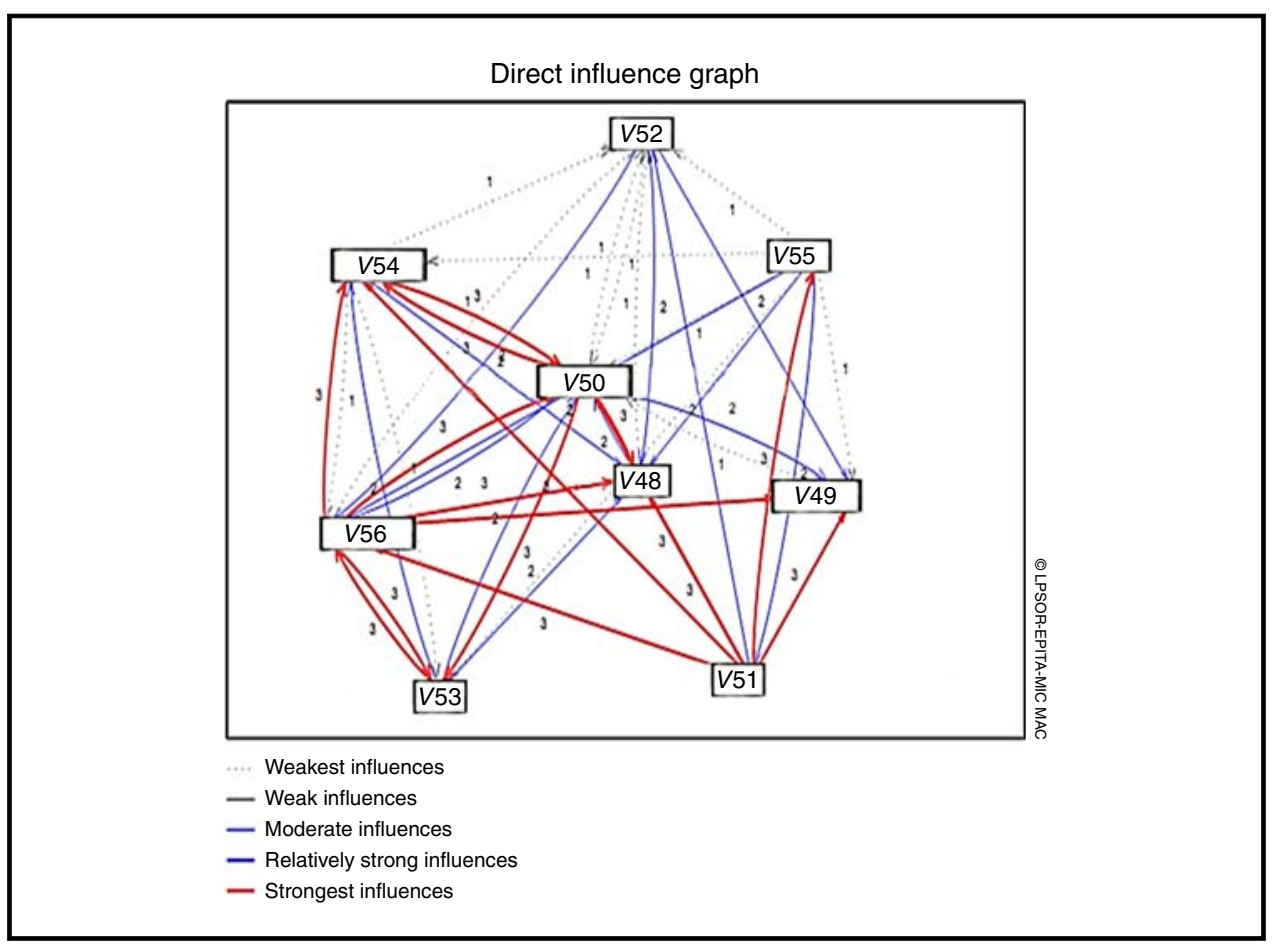

understand and analyze tourism phenomenon and to plan tourism more dynamically. In this approach, sections and factors having influence on tourism like tourists, host communities, relevant companies and organizations, environment, etc., can be examined and analyzed in an appropriate way. In other words, the system approach reflects the reality and nature of 
tourism as a coherent whole and discusses the connection between components and elements of supply section in tourism. Anyway, looking into Millennium Development Goals in 2000 and Sustainable Development Goals in 2015, the importance of systematic view in tourism development and its impacts can be easily understood. Doubtlessly, tourism and its related activities, besides irrefutable positive impacts, have negative dimensions and impacts. The positive impacts should be maximized and the negative impacts should be minimized with help of planning. However, the following question arises: what Iran pays attention to in its economic dimensions, especially positive impacts of tourism? This is due to weakness in economic system structure, considerable population migration from village to city and even from small cities to big cities, emergence of different challenges like unemployment, crimes, social disorders, traffic, boost in expansion of unauthorized residents, destruction of environmental resources, etc. In this study, what has been put under scrutiny is systematic view - of course not comprehensive - of variables related to both positive and negative aspects of economic, sociocultural, and environmental impacts. Maybe this study has been able to answer the following question: "how can we manage and organize tourism in a way to have the least negative impacts in aforementioned fields?" As it can be seen in Table I, the most important negative and positive impacts (variables) are categorized in three indicated fields. Based on examinations done in the economic field, the most important positive influential impacts include source of foreign exchange earnings, job diversity and the creation of new business opportunity, helping to boost GDP and thriving of local market. Among these variables, local market thriving has higher level of importance, as it is recognized as a discouragement for emigrating inside and outside of tourist destinations. In fact, all aforementioned impacts (variables) have interrelationships with each other and they create the butterfly effect, so that thriving of local market can lead to new employment opportunities, for establishing new small businesses and creation of some new services. The distribution of variables within the graphs represents the stability and instability of every system. Variables shown in $(L)$ form represent a stable system, and this state of system shows stability in influential variables and continuity of their influence on other variables. If the variables are distributed in (diamond) form like the right graph, the system is unstable, and a lack of influential variables threatens the system.

When the positive economic impacts are examined, variables distribution model represents a relative stable system; however, variables like investment improvement, income increase, job creation and infrastructures development are in an unstable state. Concerning negative economic impacts, attracting non-local work force and scarcity of some necessary products were recognized as the key influential factors. Variables distribution showed an unstable system in negative economic impacts of tourism. In this regard, variables like land commodification, rise in inflation and increase in living costs can be mentioned.

In the field of positive sociocultural impacts, cultural development, increase in people's awareness, identity construction and community attachment, community belonging, and reviving local values were specified as intermediate factors. The distribution of positive sociocultural impacts showed a complete unstable system, and this fact indicated an uncertain influence and a dependency of variables in this field. In the field of negative sociocultural impacts of tourism, high density of population, congestion and crowdedness along with influential change in demographic composition were specified as influential factors. Planning for identified areas can surely eliminate some tourism negative impacts in sociocultural field. The existence of some variables like distortion of local values, consumerism, demonstration effect and social gap increase is strongly in a intermediate state, and this fact has made the system behavior unpredictable.

In the field of positive/negative environmental impacts, a relative stable system can be seen. From the positive impacts' perspective, the increase in people's awareness about environment was identified as a positive influential variable. From the negative impacts' perspective, the destruction of natural and historical resources due to uncontrolled tourism development and open spaces reduction due to uncontrolled construction were identified as negative influential impacts. According to the findings of this research, tourism in Iran from the perspective of sociocultural impacts' system is strongly unstable. This issue is clearly visible in tourism destinations. The enormous role of long-term planning for the optimization of actions and considering the key variables of the system might improve the future of the sociocultural system. 
Finally, we are cautiously optimistic about the future use of the method and its potential contribution to sound sustainable development of tourism in these communities. The bases have been established and the decision-makers have shown their agreement and confidence in the process and the results.

\subsection{Implications and limitations}

The theoretical and practical limitations of the research are all issues that have been challenged in front of researchers during the research. Based on the research, important and influential limitations of this study are as follows:

1. The present study is the first study that has tried to forecast the tourism's impacts in the form of structural analysis. Therefore, the lack of similar research in the field of tourism has prevented the researchers from being aware of the problems of doing such work.

2. As with any method that is the favored approach of the group, by applying structural analysis, the authors must note that a precise choice of participants is a critical step for employing this technique. Therefore, by dominating competencies within the group, the results can be strongly biased, and in this regard, setting up a multidisciplinary team is necessary. In other words, implementing a structural analysis is a rather big operation necessitating experts' availability. So finding out experts who have enough knowledge about tourism science and future studies methodology, especially CIA, was the main challenge in front of researchers.

3. In this analysis, process must be stressed that the group can always make collective mistakes.

\subsection{Suggestions}

The research suggestions will improve the management and planning of tourism in Iran. Therefore, this research offers suggestions to the ICHTO[2]. Based on the research, we have put forward the following suggestions:

1. First, the ICHTO must adopt a strategic approach about the tourism. If the decision-makers have deep awareness regarding positive and negative impacts of tourism, they definitely will pay more attention to the programs and policies, because the necessity of attention to the tourism industry is evident in all documents of the organization's vision and mission.

2. By attracting the tourism expert labor in ICHTO and relevant organizations, the tourism planning will be done with more expertise and seriousness. Therefore, the adopted programs and policies will have an effective performance.

3. Cooperation and special partnership of tourism between responsible and operating organizations will result in having fewer challenges in implementation of tourism programs and strategies.

\section{Notes}

1. World Tourism Organization.

2. Iran Cultural Heritage, Handicraft and Tourism Organization.

\section{References}

Akins, R., Tolson, H. and Cole, B. (2005), "Stability of response characteristics of a Delphi panel: application of bootstrap data expansion", BMC Medical Research Methodology, Vol. 5 No. 37, pp. 1-12, available at: https://doi.org/10.1186/1471-2288-5-37

Alavi, J. and Yasin, M.M. (2000), "Iran's tourism potential, and market realities: an empirical approach to closing the gap", Journal of Travel \& Tourism Marketing, Vol. 9 No. 3, pp. 1-22.

Amer, M., Daim, T.U. and Jetter, A. (2013), "A review of scenario planning", Futures, Vol. 46 No. 1, pp. 23-40, available at: https://doi.org/10.1016/j.futures.2012.10.003

Andereck, K., Valentine, K. and Vogt, C. (2007), "A cross-cultural analysis of tourism and quality of life perception”, Journal of Sustainable Tourism, Vol. 15 No. 5, pp. 483-502. 
Andereck, K.L. (1995), "Environmental consequences of tourism: a review of recent research", General Technical Report - Intermountain Research Station, USDA Forest Service, No. INT-323, pp. 77-81, available at: www.cabdirect.org/cabdirect/abstract/19961806047

Andereck, K.L., Valentine, K.M., Knopf, R.C. and Vogt, C.A. (2005), "Residents' perceptions of community tourism impacts", Annals of Tourism Research, Vol. 32 No. 4, pp. 1056-76.

Apodaca, P. (2001), "Calidad y evaluación de la educación superior: situación actual y prospective (Quality and evaluation of higher education: current and prospective situation)", Revista de Investigación Educativa, Vol. 19 No. 2, pp. 367-82.

Arcade, J., Godet, M. and Roubekat, F. (1993), Structural Analysis with the MICMAC Method \& Actors' Strategy with MACTOR Method, IIEP/UNESCO publishing, Paris.

Aref, F. (2011), "Sense of community and participation for tourism development", Life Science Journal, Vol. 8 No. 1, pp. 20-5.

Aref, F., Gill, S. and Aref, F. (2010), "Tourism development in local communities: as a community development approach", Journal of American Science, Vol. 6 No. 2, pp. 155-61.

Asan, S.S. and Asan, U. (2007a), Technological Forecasting \& Social Change, Vol. 74 No. 4, pp. 627-44, available at: https://doi.org/10.1016/j.techfore.2006.05.011

Asan, S.S. and Asan, U. (2007b), “Qualitative cross-impact analysis with time consideration”, Technological Forecasting and Social Change, Vol. 74 No. 5, pp. 627-44.

Avella, J.R. (2016), "Delphi panels: research design, procedures, advantages, and challenges", International Journal of Doctoral Studies, Vol. 11 No. 1, pp. 305-21, available at: https://doi.org/10.28945/3561

Belisle, F. and Hoy, D. (1980), "The perceived impact of tourism by residents: a case study of Santa Marta, Colombia", Annals of Tourism Research, Vol. 7 No. 1, pp. 83-101.

Beni, M.C. (2001), Análise Estrutural do Turismo, 4th ed., Senac, São Paulo.

Benjumea-Arias, M., Castañeda, L. and Valencia-Arias, A. (2016), "Structural analysis of strategic variables through MICMAC use: case study. Mediterranean”, Journal of Social Sciences, Vol. 7 No. 4, pp. 11-19.

Brundtland, H. (1987), "Our common future: report of the world commission on environment and development", United Nation, Vol. 14 No. 4, pp. 291-4, available at: https://doi.org/10.1017/ S0376892900016805

Burns, P.M. and Holden, A. (1997), "Alternative and sustainable tourism development - the way forward?", in France, L. (Ed.), The Earthscan Reader in Sustainable Tourism, Earthscan Publications, London, pp. 26-8.

Cabrera, E., Cobacho, R. and Lund, J. (2002), Regional Water System Management, CRC Press, London, available at: https://doi.org/10.1201/9781439833834

Chikere, C.C. and Nwoka, J. (2015), "The systems theory of management in modern day organizations - a study of Aldgate Congress Resort Limited Port Harcourt", International Journal of Scientific and Research Publications, Vol. 5 No. 9, pp. 1-7.

Chine, L., Djeddi, T. and Haidouchi, A. (2017), "Foreign direct investment as an instrument to promote entrepreneurship in Algeria: structural analysis using MICMAC method", Journal of Business and Management Sciences, Vol. 5 No. 4, pp. 120-4.

Chiu, H.Y., Chan, C.S. and Marafa, L.M. (2016), "Local perception and preferences in nature tourism in Hong Kong”, Tourism Management Perspectives, Vol. 20 No. 1, pp. 87-97.

Choi, H. and Sirakaya, E. (2005), “Measuring residents' attitude toward sustainable tourism: development of sustainable tourism attitude scale", Journal of Travel Research, Vol. 43 No. 4, pp. 380-94.

Choi, H. and Sirakaya, E. (2006), "Sustainability indicators for managing community tourism", Tourism Management, Vol. 27 No. 6, pp. 1274-89.

Co-operation, D.A.C.O.f.E. and Development (2001), "The DAC guidelines: strategies for sustainable development: guidance for development co-operation”, OECD.

Cui, X. and Ryan, C.H. (2011), "Perceptions of place, modernity and the impacts of tourism-differences among rural and urban residents of Ankang, China: a likelihood ratio analysis", Tourism Management, Vol. 32 No. 3, pp. 604-15. 
Deery, M., Jago, L. and Fredline, L. (2012), "Rethinking social impacts of tourism research: a new research agenda”, Tourism Management, Vol. 33 No. 1, pp. 64-73.

Delgado-Serrano, M., Vanwildemeersch, P., London, S., Ortiz-Guerrero, C.E., Escalante Semerena, R. and Rojas, M. (2016), "Adapting prospective structural analysis to strengthen sustainable management and capacity building in community-based natural resource management contexts", Ecology and Society, Vol. 21 No. 2, Article No. 36, available at: http://dx.doi.org/10.5751/ES-08505-210236

Devers, K.J. and Frankel, R.M. (2000), "Study design in qualitative research: sampling and data collection strategies”, Education for Health (Abingdon), Vol. 13 No. 2, pp. 71-263.

Dewangan, D.K., Agrawal, R. and Sharma, V. (2015), "Enablers for competitiveness of Indian manufacturing sector: an ISM-fuzzy MICMAC analysis", Procedia - Social and Behavioral Sciences, Vol. 189 No. 1, pp. 416-32.

Dias, N., Curwell, S. and Bichardm, E. (2014), "The current approach of urban design, its implications for sustainable urban development”, Procedia Economics and Finance, Vol. 18 No. 1, pp. 497-504.

Dogan, H.Z. (1989), "Sociocultural impacts of tourism”, Annals of Tourism Research, Vol. 16 No. 2, pp. 216-36.

Dogru, T. and Bulut, U. (2018), "Is tourism an engine for economic recovery? Theory and empirical evidence", Tourism Management, Vol. 67 No. 1, pp. 425-34.

Drumm, A., Moore, A., Soles, A., Patterson, C. and Terborgh, J.E. (2004), "The business of ecotourism development and management. Ecotourism development: a manual for conservation planners and managers", The Nature Conservancy, Arlington, VA, Vol. 2, available at: www.cbd.int/financial/greenmarkets/ g-greenecotoursm-undp.pdf

Duperrin, J.C. and Godet, M. (1973), "Hierarchization method for the elements of a system. An attempt to forecast a nuclear energy system in its societal context (CEA-R-4541)", available at: http://inis.iaea.org/ search/search.aspx?orig_q=RN:05115595 ER

Dyer, P., Gursoy, D., Sharma, B. and Carter, J. (2007), "Structural modeling of resident perceptions of tourism and associated development on the Sunshine Coast, Australia", Tourism Management, Vol. 28 No. 2, pp. 409-22.

Easterling, D. (2008), "Residents and tourism: what is really at stake", Journal of Travel and Tourism Marketing, Vol. 18 No. 4, pp. 49-64.

Edwards, D., Griffin, T. and Hayllar, B. (2008), "Urban tourism research: developing an agenda", Annals of Tourism Research, Vol. 35 No. 4, pp. 1032-52.

Esmaeil Zaei, M. and Esmaeil Zaei, M. (2013), "The impacts of tourism industry on host community", European Journal of Tourism Hospitality and Research, Vol. 1 No. 2, pp. 12-21.

Foroutan, M., Dalvand, S., Daryani, A., Ahmadpour, E., Majidiani, H., Khademvatan, S. and Abbasi, E. (2017), "Rolling up the pieces of a puzzle: a systematic review and meta-analysis of the prevalence of toxoplasmosis in Iran", Alexandria Journal of Medicine, Vol. 54 No. 3, pp. 189-96.

Georghiou, L., Cassingena, J., Keenen, M., Miles, I. and Popper, R. (2012), "Manual de prospectiva tecnológica. Conceptos y práctica (Technological Prospective Manual. Concepts and Practice)", Flacso México, available at: www.flacso.edu.mx/publicaciones/novedades/Manual-de-prospectiva-tecnologica-

Getz, D. (2008), "Event tourism: definition, evolution, and research”, Tourism Management, Vol. 29 No. 3, pp. 403-28.

Ghaderi, Z. and Henderson, J.C. (2012), "Sustainable rural tourism in Iran: a perspective from Hawraman village”, Tourism Management Perspectives, Vol. 2 No. 3, pp. 47-54.

Glenn, J.C. (2003), "Introduction to the futures research methods series", in Glenn, J.C. and Gordon, T.J. (Eds), Futures Research Methodology V2.0, United Nations University, Millennium-Project, available at: http:// forlearn.jrc.ec.europa.eu/guide/A2_references/frm.htm

Glenn, J.C. and Gordon, T.J. (2003), AC/UNU Millennium Project: Futures Research Methodology - V2.0, AC/UNU, Washington, DC.

Godet, M. (2000), "The art of scenarios and strategic planning: tools and pitfalls", Technological Forecasting and Social zChange, Vol. 65 No. 1, pp. 3-22.

Godet, M., Durance, P.H. and Gerber (2008), "Strategic foresight (la prospective): use and misuse of scenario building", LIPSOR Working Paper (Cahiers du LIPSOR). 
Goeldner, C.R. and Ritchie, J.B. (2012), Tourism: Principles, Practices and Philosophies, 12th ed., John Wiley and Sons, Hoboken, NJ.

Gordon, T. and Hayward, H. (1968), "Initial experiments with the cross impact matrix method of forecasting", Futures, Vol. 1 No. 2, pp. 100-16.

Gordon, T.J. (2009), "Cross-impact analysis", in Glenn, J.C. and Gordon, T.J. (Eds), Futures Research Methodology, Version 3.0, The Millennium Project.

Hall, C.M., Duval, D. and Timothy, D. (2004), Safety and Security in Tourism': Relationships, Management and Marketing, Haworth Press, New York, NY.

Holden, A. (2009), "The environment-tourism nexus: influence of market ethics", Annals of Tourism Research, Vol. 36 No. 3, pp. 373-89.

Inayatullah, S. (2013), "Futures studies: theories and methods", in Jonquiere, F.G. (Ed.), There's a Future: Visions for a Better World, BBVA, Madrid, pp. 36-66.

Inskeep, E. (1991), Tourism Planning: An Integrated and Sustainable Development Approach, Van Nostrand Reinhold, New York, NY, p. 508.

Jaafar, M., Rasoolimanesh, S.M. and Ismail, S. (2017), "Perceived sociocultural impacts of tourism and community participation: a case study of Langkawi Island", Tourism and Hospitality Research, Vol. 17 No. 2, pp. 123-34, available at: https://doi.org/10.1177/1467358415610373

Jackson, M.C. (2003), Systems Thinking, Creative Holism for Managers, John Wiley and Sons, Chichester. Jackson, M.S. and Inbakaran, R.J. (2006), “Evaluating residents' attitudes and intentions to act towards tourism development in regional Victoria, Australia”, International Journal of Tourism Research, Vol. 8 No. 5, pp. 355-66.

Johnson, J., Snepenger, D. and Akis, S. (1994), “Residents' perceptions of tourism development”, Annals of Tourism Research, Vol. 21 No. 3, pp. 629-37.

Khodadadi, M. (2016), "Challenges and opportunities for tourism development in Iran: perspectives of Iranian tourism suppliers", Tourism Management Perspectives, Vol. 19, Part A, pp. 90-2.

Kreibich, R., Oertel, B. and Wolk, M. (2012), "Futures studies and future-oriented technology analysis principles", Methodology and Research Questions, HIIG Discussion Paper Series No. 2012-05, available at: http://dx.doi.org/10.2139/ssrn.2094215

Lee, C.-K., Kim, S.-S. and Kang, S. (2003), "Perceptions of casino impacts: a Korea longitudinal study", Tourism Management, Vol. 24 No. 1, pp. 45-55.

Leiper, N. (1990), The Tourism System, Palmerston North, New Zealand Massey University Department of Management Systems.

Lin, N. (2001), Social Capital: A Theory of Social Structure and Action, Cambridge University Press, New York, NY, p. 45.

Liu, J.C. and Var, T. (1986), "Residents attitudes toward tourism impacts in Hawaii", Annals of Tourism Research, Vol. 13 No. 2, pp. 193-214.

Lundberg, E. (2016), "The importance of tourism impacts for different local resident groups: a case study of a Swedish seaside destination”, Journal of Destination Marketing \& Management, Vol. 6 No. 1, pp. 46-55.

McGehee, N. and Andereck, K. (2004), "Factors predicting rural residents' support of tourism", Journal of Travel Research, Vol. 43 No. 2, pp. 131-40.

Mahdizade, J. (2007), Urban Strategic Planning, Tarh Nashr Press, Tehran (in Persian).

Marzuki, A. (2011), "Resident attitudes towards impacts from tourism development in Langkawi Islands, Malaysia”, World Applied Sciences Journal, Vol. 12, Special Issue of Tourism \& Hospitality, pp. 25-34.

Mason, P. (2003), Tourism Impacts, Planning and Management, Butterworth-Heinemann, available at: https://trove.nla.gov.au/version/34300840

Mill, R.C. and Morrison, A.M. (2002), The Tourism System, 4th ed., Kendall/Hunt Publishing Company, Dubuque, IA.

Neuman, L.W. (2007), Social Research Methods, 6th ed., Pearson Education, Upper Saddle River, NJ.

Perez, E.A. and Nadal, J.R. (2005), "Host community perceptions a cluster analysis", Annals of Tourism Research, Vol. 32 No. 4, pp. 925-41. 
Postma, A. and Schmuecker, D. (2017), "Understanding and overcoming negative impacts of tourism in city destinations: conceptual model and strategic framework", Journal of Tourism Futures, Vol. 3 No. 2, pp. 144-56.

Rizal, p. and Asokan, R. (2014), "Emerging environmental issues with the development of tourism industry in India: a study", International Journal of Development Research, Vol. 4 No. 5, pp. 995-9.

Saricam, C., Kalaoglu, F. and Polat, S. (2012), "Determination of the key variables for future anticipation in Turkish apparel industry”, Tekstil ve Konfeksiyon, Vol. 22 No. 2, pp. 137-43.

Schlange, L.E. and Jüttner, U. (1997), "Helping managers to identify the key strategic issues", Long Range Plan, Vol. 30 No. 5, pp. 777-86.

Schnaars, S.P. (1987), "How to develop and use scenarios", Long Range Plan, Vol. 20 No. 1, pp. 105-14.

Shaker, R.R. and Sirodoev, I.G. (2016), "Assessing sustainable development across Moldova using household and property composition indicators", Habitat International, pp. 1-13.

Sharma, B., Dyer, P., Carter, J. and Gursoy, D. (2008), “Exploring residents' perceptions of the social impacts of tourism on the Sunshine Coast, Australia", International Journal of Hospitality and Tourism Administration, Vol. 9 No. 3, pp. 288-311.

Sharpley, R. (2014), "Host perceptions of tourism: a review of the research", Tourism Management, Vol. 42 No. 1, pp. 37-49.

Sheldon, P. and Var, T. (1984), "Resident's attitudes toward tourism in North Wales", Tourism Management, Vol. 5 No. 1, pp. 40-7.

Tohidy, F. (2011), "Economic impacts of tourism industry", International Journal of Business and Management, Vol. 6 No. 8, pp. 206-15.

Tosun, C. (2002), "Host perceptions of impacts: a comparative tourism study", Annals of Tourism Research, Vol. 29 No. 1, pp. 231-53.

Uysal, Ü.E. (2015), Urban Tourism in Istanbul: Urban Regeneration, Mega-events and City, Marketing and Branding, Academic dissertation, University of Helsinki, available at: https://helda.helsinki.fi/bitstream/handle/ 10138/152740/UrbanTou.pdf?sequence=1

Villacorta, P.J., Masegosa, A.D., Castellanos, D. and Lamata, M.T., (2014), "A new fuzzy linguistic approach to qualitative cross impact analysis", Applied Soft Computing, Vol. 24 No. 1, pp. 19-30.

Vishwanatha, S. and Chandrashekara, B. (2014), "A study on the environmental impacts of ecotourism in Kodagu district, Karnataka", American Journal of Research Communication, Vol. 2 No. 4, pp. 256-65.

Wanwara-Mbugua, L.W. and Cornwell, T.B. (2008), "The impact of tourism on theconsumption environment: coping and potential praxis in Malindi, Kenya", African Journal of Bussiness Management, Vol. 2 No. 6, pp. 99-110.

Weihrich, H., Koontz, H. and Cannice, M.V. (2008), Management: A Global and Entrepreneurial Perspective, Tata McGraw-Hill, New Delhi.

Williams, D.R., McDonald, C.D., Riden, C.M. and Uysal, M. (1995), "Community attachment, regional identity and resident attitudes toward tourism", Proceedings of the 26th Annual Travel and Tourism Research Association Conference, pp. 424-8.

Wu, S.T. and Chen, Y.S. (2015), "The social, economic, and environmental impacts of casino gambling on the residents of Macau and Singapore”, Tourism Management, Vol. 48 No. 5, pp. 285-98.

Yoon, Y., Gursoy, D. and Chen, J. (2001), "Validating a tourism development theory with structural equation modeling", Tourism Management, Vol. 22 No. 4, pp. 363-72.

Zhou, Y. (1986), "Discuss on tourism environment protection in China", Tourism Tribune, Vol. 1 No. 3, pp. 29-35 (in Chinese).

\section{Further reading}

Sharma, B. and Dyer, P. (2012), "A longitudinal study of the resident's perceptions of tourism impacts using data from the sunshine coast Australia", Revista de Turismo y Patrimonio Cultural, Vol. 10 No. 2, pp. 37-46.

Williams, S.W. (2009), Tourism Geography: A New Synthesis, 2nd ed., Routledge, New York, NY. 


\section{Appendix}

Table Al Profile of experts

\begin{tabular}{|c|c|c|}
\hline Participants & Education & Organizational position \\
\hline P1 & PhD in urban planning & Assistant Professor, Faculty of Geography at University of Tehran \\
\hline P2 & PhD student in economic science & PhD Student in Economic Science, Faculty of Economics at University of Tehran \\
\hline P3 & $\mathrm{PhD}$ in tourism planning & Assistant Professor, Faculty of Tourism Management at Science and Culture University \\
\hline P4 & PhD in business administration & $\begin{array}{l}\text { Associated Professor, Faculty of Tourism Management (marketing orientation) at University of } \\
\text { Tehran }\end{array}$ \\
\hline P5 & PhD in urban planning & Assistant Professor, Faculty of Urban Affairs at University of Tehran \\
\hline P6 & $\mathrm{PhD}$ in urbanism and planning offers & Assistant Professor, Faculty of Urban Management at Science and Culture University \\
\hline P7 & $\mathrm{PhD}$ in political geography & Assistant Professor, Faculty of Urban Affairs at University of Tehran \\
\hline P8 & $\mathrm{PhD}$ in human geography & Assistant Professor, Faculty of Urban Affairs at University of Tehran \\
\hline P9 & PhD in rural geography and planning & Assistant Professor, Faculty of Geography at University of Tehran \\
\hline P10 & $\mathrm{PhD}$ in tourism management & Assistant Professor, Faculty of Tourism Management at Science and Culture University \\
\hline P11 & $\mathrm{PhD}$ in geography and urban planning & Associate Professor, Faculty of Geography at University of Tehran \\
\hline P12 & $\mathrm{PhD}$ in tourism management & Assistant Professor, Faculty of Entrepreneurship at University of Tehran \\
\hline P13 & $\mathrm{PhD}$ in tourism management & Assistant Professor, Faculty of Tourism Management at Science and Culture University \\
\hline P14 & $\mathrm{PhD}$ in rural geography and planning & Associated Professor, Faculty of Geography at University of Tehran \\
\hline P15 & $\mathrm{PhD}$ in tourism management & Assistant Professor, Faculty of Tourism Management at Science and Culture University \\
\hline P16 & $\mathrm{PhD}$ in geography and urban planning & Associated Professor, Faculty of Geography at University of Tehran \\
\hline P17 & $\mathrm{PhD}$ in tourism management & Assistant Professor, Faculty of Entrepreneurship at University of Tehran \\
\hline P18 & $\mathrm{PhD}$ in tourism management & Assistant Professor, Faculty of Tourism Management at Science and Culture University \\
\hline P19 & $\mathrm{PhD}$ in tourism management & Assistant Professor, Faculty of Tourism Management at Science and Culture University \\
\hline P20 & $\begin{array}{l}\text { PhD in geography and urban } \\
\text { planning }\end{array}$ & Associate Professor, Faculty of Geography at University of Tehran \\
\hline P21 & $\mathrm{PhD}$ in tourism management & Associated Professor, Faculty of Entrepreneurship at University of Tehran \\
\hline P22 & $\mathrm{PhD}$ in tourism management & Assistant Professor, Faculty of Tourism Management at Science and Culture University \\
\hline P23 & PhD in rural geography and planning & Associated Professor, Faculty of Geography at University of Tehran \\
\hline P24 & $\mathrm{PhD}$ in tourism management & Associated Professor, Faculty of Tourism Management at Science and Culture University \\
\hline P25 & $\mathrm{PhD}$ in geography and urban planning & Associated Professor, Faculty of Geography at University of Tehran \\
\hline P26 & $\mathrm{PhD}$ in tourism management & Associated Professor, Faculty of Entrepreneurship at University of Tehran \\
\hline P27 & $\mathrm{PhD}$ in tourism management & Associated Professor, Faculty of Tourism Management at Science and Culture University \\
\hline
\end{tabular}

\section{Corresponding author}

Amin Faraji can be contacted at: a.faraji@ut.ac.ir

For instructions on how to order reprints of this article, please visit our website: 